\title{
Effect of AMOC collapse on ENSO in a high resolution general circulation model
}

\author{
Mark S. Williamson ${ }^{1}$ (D) Mat Collins ${ }^{2} \cdot$ Sybren S. Drijfhout $^{3} \cdot$ Ron Kahana $^{4} \cdot$ \\ Jennifer V. Mecking ${ }^{3} \cdot$ Timothy M. Lenton ${ }^{1}$
}

Received: 12 January 2017 / Accepted: 7 June 2017 / Published online: 17 June 2017

(c) The Author(s) 2017. This article is an open access publication

\begin{abstract}
We look at changes in the El Niño Southern Oscillation (ENSO) in a high-resolution eddy-permitting climate model experiment in which the Atlantic Meridional Circulation (AMOC) is switched off using freshwater hosing. The ENSO mode is shifted eastward and its period becomes longer and more regular when the AMOC is off. The eastward shift can be attributed to an anomalous eastern Ekman transport in the mean equatorial Pacific ocean state. Convergence of this transport deepens the thermocline in the eastern tropical Pacific and increases the temperature anomaly relaxation time, causing increased ENSO period. The anomalous Ekman transport is caused by a surface northerly wind anomaly in response to the meridional sea surface temperature dipole that results from switching the AMOC off. In contrast to a previous study with an earlier version of the model, which showed an increase in ENSO amplitude in an AMOC off experiment, here the amplitude remains the same as in the AMOC on control state. We attribute this difference to variations in the response of decreased stochastic forcing in the different models, which competes with the reduced damping of temperature anomalies. In the new high-resolution model,
\end{abstract}

Mark S. Williamson

m.s.williamson@exeter.ac.uk

1 Earth System Science Group, College of Life and Environmental Sciences, University of Exeter, Laver Building, North Park Road, Exeter EX4 4QE, UK

2 College of Engineering, Mathematics and Physical Sciences, University of Exeter, Exeter, UK

3 Ocean and Earth Science, National Oceanography Centre Southampton, University of Southampton, Southampton SO14 3ZH, UK

4 Hadley Centre, Met Office, Exeter, UK these effects approximately cancel resulting in no change in amplitude.

Keywords ENSO - AMOC A AMOC collapse $\cdot$ Abrupt climate change $\cdot$ Hosing experiment $\cdot$ CGCM

\section{Introduction}

The net transport of heat from the equator to higher northern latitudes in the Atlantic caused by the flow of upper water layers in the Atlantic ocean, part of the Atlantic meridional overturning circulation (AMOC), is responsible for the mild winters in western Europe. This net ocean flow is part of a larger ocean mode known as the thermohaline circulation. Simple models of this circulation show tipping point like behaviour i.e. they can abruptly switch from one mode to another when changes in climatic conditions are comparatively small and slow (Stommel 1961; Rooth 1982; Marotzke and Willebrand 1991). It has been shown that the Atlantic branch of this circulation can abruptly switch off under certain conditions causing major changes in the climate not only in the North Atlantic but also globally (Vellinga and Wood 2002; Stouffer et al. 2006; Jackson et al. 2015). It is thought that this has happened in the past Earth history (Dansgard-Oeschger events and Heinrich stadials, Rahmstorf 2002; Clement and Peterson 2006) and although present research suggests a collapse of the Atlantic MOC is unlikely to occur in the 21 st century under global warming scenarios (Collins et al. 2013), the impacts of a shutdown are severe making it a low probability high impact event. Even though a shutdown is thought to be unlikely by the end of the 21 st century, a weakening in AMOC was assessed to be very likely by the IPCC AR5 (Collins et al. 
2013) making assessment of the impacts of this tipping point, both regional and global, a useful exercise.

In future climate model projections, emissions are prescribed causing a reduction or perhaps a shutdown of the AMOC indirectly along with other climate impacts. The work reported here differs in that only the impacts of AMOC shutdown are assessed. This is done by forcing a high resolution Earth system model into a collapsed AMOC state directly using a large salinity perturbation applied for 10 years, without changing anything else (such as emissions). The AMOC off state in this simulation is stable over the 450 years duration of the model integration (Mecking et al. 2016) which is then compared with a control run making the study a comparatively clean assessment of the impacts of AMOC shutdown. The model used is a state of the art global climate model (HadGEM3), a high resolution general circulation model with coupled ocean, atmosphere, sea ice and land surface and hydrology.

Similar 'freshwater hosing' experiments have been performed with models of differing complexity, from other coupled GCMs (Vellinga and Wood 2002) to models of intermediate complexity (Rahmstorf et al. 2005). In these studies, removing such a large ocean flux of heat into the North Atlantic causes a large reorganization of the global climate, amongst these impacts there is substantial cooling around the North Atlantic region and a southward shift in the intertropical convergence zone (ITCZ).

We look in particular at the differences in ENSO resulting from the global climatic changes that collapse of the AMOC can induce in the model. ENSO is a coupled ocean-atmosphere oscillatory mode in the equatorial Pacific and the dominant global mode of natural unforced variability. Its effects are large enough to change the typical global climate patterns. ENSO oscillates between two states, a warm state, El Niño, and a cold state, La Niña, with a period of around 3-7 years. Typically the western side of the equatorial Pacific has some of the highest sea surface temperatures (SSTs) on the planet. This 'warm pool' causes a net wind to blow east to west pushing surface waters westward and causing a depression in the western Pacific thermocline and a lifting of the thermocline in the east. This lifting in the east causes cold, nutrient rich deep waters to upwell off the South American coast. Every few years this quasi-steady phase breaks down, the net wind ceases, the thermocline adjusts to the new pressure gradient and the warm pool propagates west to east across the Pacific in an El Niño event causing the SSTs in the the east to rise and the thermocline to deepen inhibiting the cold waters from upwelling. This is a large scale energy readjustment on the global scale and changes typical weather patterns significantly.

Making concrete statements on ENSO behaviour has proved difficult due to the delicate balance of ocean and atmosphere feedbacks that determine its characteristics (Collins et al. 2010). In modelling studies, decadal or centennial modulations can be generated without any change in external forcing (Wittenberg 2009). Including changing forcing and changing mean conditions makes attributing changes even more difficult. Because of this sensitive balance different models forced with the same boundary conditions have produced a wide range of ENSO behaviours (Bellenger et al. 2014).

There have also been studies of ENSO in hosed, weakened AMOC runs of CMIP3 era models (Timmerman et al. 2007; Dong and Sutton 2007) and in most models there was a substantial weakening of the annual cycle in the eastern equatorial Pacific and an increase in ENSO amplitude. Both of these traits were found in HadCM3 (an earlier generation of the Met Office Hadley Centre model) as well as an eastern shift in the ENSO mode (Dong and Sutton 2007). We find the same eastern shift and weakened annual cycle in HadGEM3 however they differ in ENSO period response, going to longer periods in HadGEM3 (there was no significant change in HadCM3) and the amplitude remains approximately the same (HadCM3 ENSO amplitude increased by about a third).

Using a stochastically forced damped oscillator model of slow ENSO dynamics introduced by Jin (1997) to qualitatively understand the response of the much more complicated HadGEM3, we suggest the difference in ENSO amplitude between the different models is due to the balance of changes in ENSO damping and the magnitude of stochastic forcing. To be more concrete, reduced damping in this model means larger amplitude ENSO oscillations for a fixed forcing magnitude. In the AMOC off run this reduced damping is caused by the increased eastern Pacific temperature anomaly relaxation times from the deeper thermocline. Thus higher ENSO amplitudes should result. However, the decreased stochastic forcing of the oscillations offsets this increase. The overall ENSO amplitude is therefore a competition between these two competing effects.

In Sect. 2 we describe the model and experiment design. In Sect. 3 we briefly describe the model states in both AMOC off and control runs before analyzing the dominant tropical Pacific modes of variability, their amplitudes, power spectra and autocorrelation functions and differences between the simulations. In Sect. 4 we provide mechanisms and the supporting evidence for the differences between the ENSOs in both simulations and discuss these results in the context of previous findings in Sect. 5. Conclusions are given in Sect. 6. 


\section{Model setup and experiment design}

\subsection{Model description}

The model and its performance has previously been described in detail elsewhere (Williams et al. 2015). To repeat pertinent details, the model is the Global Coupled 2.0 model (GC2) configuration of the HadGEM3 model (Hewitt et al. 2011). This consists of an atmosphere, ocean, sea-ice and land-surface models. The atmosphere model is Global Atmosphere vn6.0 (GA6) (Demory et al. 2013) of the Met Office unified model at N216 horizontal resolution and 85 levels in the vertical. The ocean model is the Global Ocean 5 (GO5) (Megann et al. 2013) version of the ORCA025 configuration of the NEMO model (Madec 2008) with a eddy permitting horizontal resolution of $0.25^{\circ}$ and 75 vertical levels. The sea-ice model is version 4.1 of the Los Alamos National Laboratory sea-ice model, CICE (Hunke and Lipscomb 2010) and resolution is the same as that of the ocean model. The land model used in GC2 is the GL6 configuration of the Joint UK Land Environment Simulator (JULES). The model simulates the state of the soil and 5 vegetation types [broadleaf trees, needleleaf trees, $\mathrm{C} 3$ (temperate) grass, C4 (tropical) grass, and shrubs] in each land grid box. The distribution of these plant types is fixed throughout the simulations.

\subsubsection{Experiment design}

Details of the experimental design and of the runs we analyze here have also been given previously (Jackson et al. 2015; Mecking et al. 2016). Two runs of the model are compared, a steady state control run (the AMOC is in its usual on state in this run) and an AMOC off steady state run. To do this the model was initialised from climatology and spun up for over 36 years. The control run is then integrated for a further 150 years. To collapse the AMOC the methodology of Vellinga and Wood (2002) is used which involves perturbing the salinity in the upper layers of the North Atlantic to inhibit deep convection and hence quickly shut down the AMOC (the absence of the sinking branch of the AMOC is what we will refer to as the AMOC off state). Although this method of collapsing the AMOC is unrealistic (freshwater addition from melt of the Greenland ice sheet and Arctic runoff are the most likely cause of AMOC shutdown in global warming projections) it is useful for investigating the impacts of a shutdown. The AMOC off run is initialised after 42 years of the control run. Instantaneous salinity perturbations are applied to the upper $536 \mathrm{~m}$ of the Atlantic and Arctic Ocean north of $20^{\circ} \mathrm{N}$ each December for the first 10 years at which point hosing ceases. Each salinity perturbation is equivalent to continuously adding freshwater at a rate of $1 \mathrm{~Sv}\left(1 \mathrm{~Sv}=10^{6} \mathrm{~m}^{3} / \mathrm{s}\right)$ for 10 years (total of 10 $\mathrm{SvYr}$ ). As is common practice in hosing experiments the salinity in the rest of the ocean is also perturbed such that the total freshwater content of the global ocean remains constant. The AMOC off run is integrated for a total of 450 years from the start of the salinity perturbations. No external forcing is applied to the model apart from diurnal and annual cycles of the radiative fluxes. Atmospheric $\mathrm{CO}_{2}$ concentrations are fixed to 1978 levels.

As the perturbations are applied, the AMOC collapses from the steady $\sim 15 \mathrm{~Sv}$ (maximum streamfunction at $26.5^{\circ} \mathrm{N}$ ) in the control run and remains very weak for the full model simulation period of 450 years. As a result meridional Atlantic ocean heat transport at $30^{\circ} \mathrm{N}$ is halved from $\sim 1$ to $\sim 0.5 \mathrm{PW}$ and surface air temperature (SAT) is reduced by $\sim 4{ }^{\circ} \mathrm{C}$ in the North Atlantic (Jackson et al. 2015). The AMOC off simulation is approximately stationary 60 years after the salinity perturbations end however the maximum in the AMOC streamfunction at $26.5^{\circ} \mathrm{N}$ does have a very slow increasing trend reaching $5 \mathrm{~Sv}$ at the end of the 450 years. Further north however, the AMOC shows no signs of recovering (Mecking et al. 2016, see Fig. 1).
Fig. 1 Maximum in the AMOC streamfunction at $26.5^{\circ} \mathrm{N}$ and $50-65^{\circ} \mathrm{N}$ between depths of 500 and $2000 \mathrm{~m}$. Blue line is the control, red line is the AMOC off run. Hosing is applied for 10 years at the beginning of the AMOC off run resulting in a relatively stable off state for the remaining duration of the simulation. The last 300 years of the AMOC off run and the full 150 years of the control run are analyzed in the rest of the manuscript
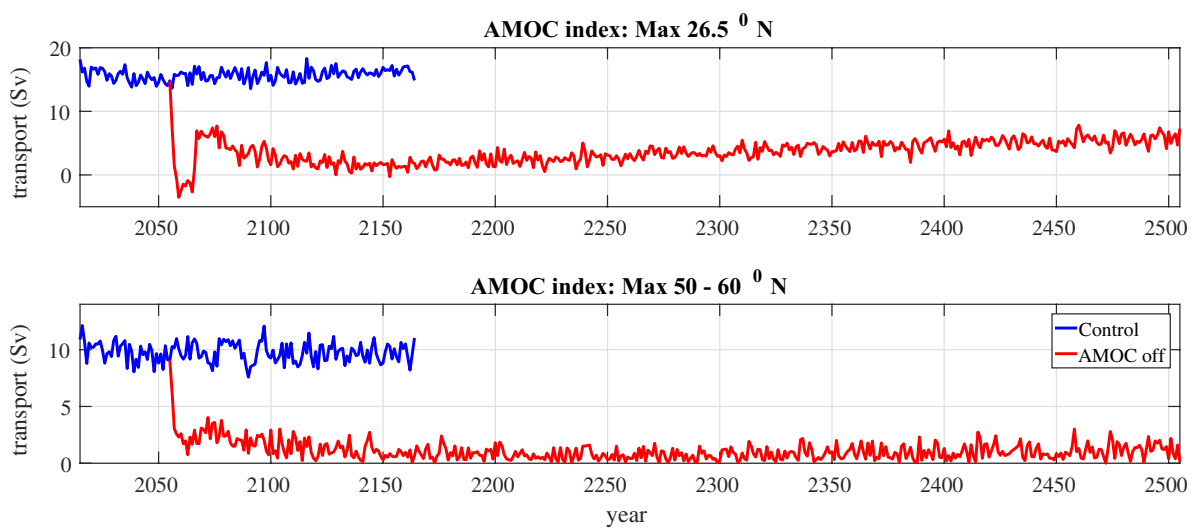
In the following analysis we use all 150 years of the control run and the last 300 years of the AMOC off run to determine ENSO properties.

\section{Results}

\subsection{Climate in the HadGEM3 control run}

General information on the climate states of the control (Williams et al. 2015) and AMOC off runs have been given previously in Jackson et al. (2015) and Mecking et al. (2016) and we give brief details here.

One of the robust feature of hosing simulations is the widespread cooling particularly in the North Atlantic and northern hemisphere in general (Stouffer et al. 2006; Vellinga and Wood 2002, Fig. 2). This is accompanied by a slight warming in the southern hemisphere to give the well known anomalous cool northern hemisphere-warm southern hemisphere dipole, southward shift in the intertropical convergence zone (ITCZ) and associated changes in equatorial precipitation patterns as a new energy balance between the hemispheres is reached. The north Atlantic cooling results in more Arctic sea-ice and intensification of storm tracks (Jackson et al. 2015). Globally, the annual mean SAT is lower when the AMOC is off $\left(15.1{ }^{\circ} \mathrm{C}\right.$ compared to $16.2{ }^{\circ} \mathrm{C}$ in the control run). Variability in global annual mean SAT is increased in the AMOC off run (standard deviations of $1.52{ }^{\circ} \mathrm{C}$ in the AMOC off and $1.33{ }^{\circ} \mathrm{C}$ in the control) although the reverse is true in the annual mean taken over the tropical Pacific region (standard deviations of $0.52{ }^{\circ} \mathrm{C}$ in the AMOC off and $0.67{ }^{\circ} \mathrm{C}$ in the control).
One of the unique features of the HadGEM3 simulations is the stability of the AMOC off state. Usually the AMOC off state recovers when freshwater hosing is removed. Here it remains stable. Mecking et al. (2016) report that this is due to the eddy permitting ocean model allowing for a stronger northward freshwater transport.

HadGEM3 in GC2 configuration was shown to be an improvement over previous versions of the Met Office Hadley Centre model particularly in the modes of variability such as mid-latitude and tropical cyclone intensities, the Madden-Julian Oscillation (MJO) and ENSO (Williams et al. 2015). Excess equatorial easterly wind stress has been a problem in previous versions of Met Office models. A number of changes have made this better including the improvement of MJO simulation, although its amplitude remains significantly weaker than observed, which can be a source of westerly wind bursts that initiate El Niño events. Higher horizontal ocean resolution has also improved ENSO simulation (good spatial pattern, SST variability). ENSO period also falls in to the observed range of 3-7 years with no dominant 2 year or longer period peaks in the power spectrum that have been a problem in older coupled GCMs (Bellenger et al. 2014). Overall the model compares well with a range of CMIP5 models (Bellenger et al. 2014) and historical observations. The control run however slightly underestimates SST variability, more so in the western tropical Pacific and the distribution of SST anomalies is slightly skewed towards cold events whereas in observations a warm skew is more typically present. SST statistics in the control run and historical observations (1870-2015) are given in Table 1 although it should be noted the comparison is not completely equivalent as

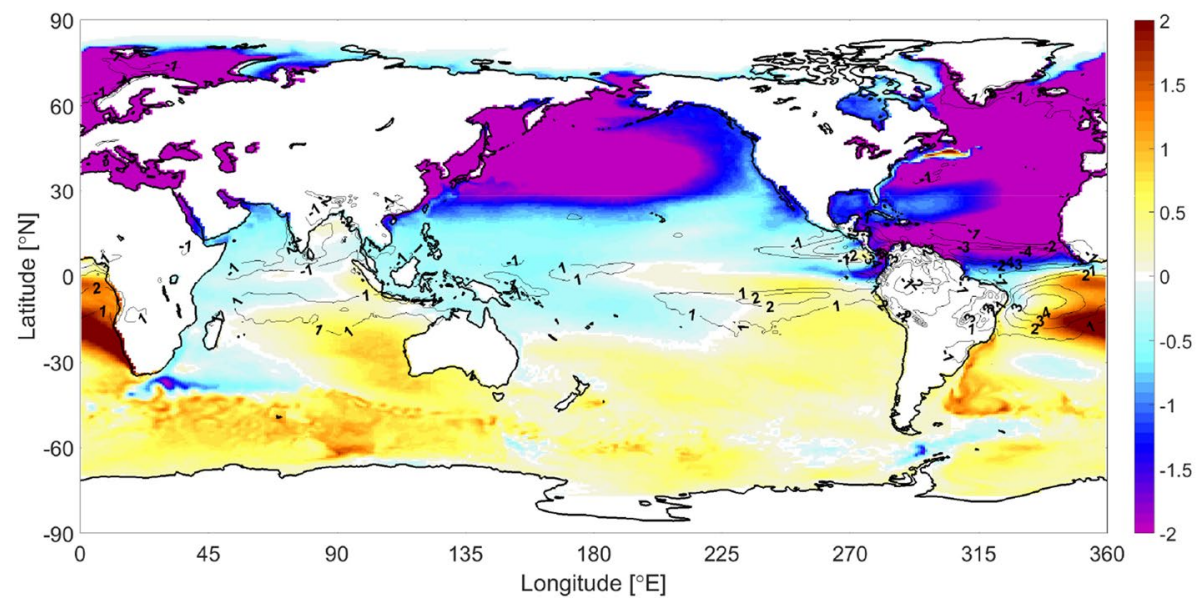

Fig. 2 Global patterns of the annual mean sea surface temperature (SST) anomaly (AMOC off-control) in the colour plot. The scale is in ${ }^{\circ} \mathrm{C}$. There is a widespread cooling particularly in the North Atlantic and northern hemisphere in general. This is accompanied by a slight warming in the southern hemisphere to give the well known anoma- lous cool northern hemisphere-warm southern hemisphere dipole when the AMOC is off. The black contour lines are the annual mean precipitation anomaly in $\mathrm{mm} /$ day. Generally, when the AMOC is off the northern hemisphere becomes drier and the and southern hemisphere becomes wetter. The ITCZ is also shifted southward 
Table 1 Mean, standard deviation and skewness of the deseasonalized leading SST EOF and the same for the Niño regions in the control run, AMOC off run and historical observations

\begin{tabular}{llll}
\hline & Observations & Control & AMOC off \\
\hline Mean Niño 1 + 2 SST & $23.23{ }^{\circ} \mathrm{C}$ & $25.45{ }^{\circ} \mathrm{C}$ & $25.48{ }^{\circ} \mathrm{C}$ \\
Mean Niño 3 SST & $25.74{ }^{\circ} \mathrm{C}$ & $26.70{ }^{\circ} \mathrm{C}$ & $26.73{ }^{\circ} \mathrm{C}$ \\
Mean Niño 3.4 SST & $26.96{ }^{\circ} \mathrm{C}$ & $27.68{ }^{\circ} \mathrm{C}$ & $27.69{ }^{\circ} \mathrm{C}$ \\
Mean Niño 4 SST & $28.37{ }^{\circ} \mathrm{C}$ & $28.93{ }^{\circ} \mathrm{C}$ & $28.85{ }^{\circ} \mathrm{C}$ \\
Niño 1 + 2 std (monthly mean removed) & $2.25(0.91){ }^{\circ} \mathrm{C}$ & $2.21(0.96){ }^{\circ} \mathrm{C}$ & $2.31(1.07){ }^{\circ} \mathrm{C}$ \\
Niño 3 std (monthly mean removed) & $1.19(0.80){ }^{\circ} \mathrm{C}$ & $1.13(0.81){ }^{\circ} \mathrm{C}$ & $0.96(0.80){ }^{\circ} \mathrm{C}$ \\
Niño 3.4 std (monthly mean removed) & $0.89(0.77){ }^{\circ} \mathrm{C}$ & $0.77(0.73){ }^{\circ} \mathrm{C}$ & $0.69(0.65){ }^{\circ} \mathrm{C}$ \\
Niño 4 std (monthly mean removed) & $0.60(0.57){ }^{\circ} \mathrm{C}$ & $0.52(0.42){ }^{\circ} \mathrm{C}$ & $0.52(0.35){ }^{\circ} \mathrm{C}$ \\
Niño 1 + 2 skew (monthly mean removed) & $0.19(1.13){ }^{\circ} \mathrm{C}^{3}$ & $-0.04(0.16){ }^{\circ} \mathrm{C}^{3}$ & $-0.23(0.33){ }^{\circ} \mathrm{C}^{3}$ \\
Niño 3 skew (monthly mean removed) & $0.14(0.76){ }^{\circ} \mathrm{C}^{3}$ & $-0.23(-0.30){ }^{\circ} \mathrm{C}^{3}$ & $-0.23(-0.31){ }^{\circ} \mathrm{C}^{3}$ \\
Niño 3.4 skew (monthly mean removed) & $-0.04(0.41){ }^{\circ} \mathrm{C}^{3}$ & $-0.51(-0.46){ }^{\circ} \mathrm{C}^{3}$ & $-0.51(-0.46){ }^{\circ} \mathrm{C}^{3}$ \\
Niño 4 skew (monthly mean removed) & $-0.23(-0.10){ }^{\circ} \mathrm{C}^{3}$ & $-0.53(-0.88){ }^{\circ} \mathrm{C}^{3}$ & $-0.44(-0.91){ }^{\circ} \mathrm{C}^{3}$ \\
EOF std & N/A & $41.70{ }^{\circ} \mathrm{C}$ & $39.02{ }^{\circ} \mathrm{C}$ \\
EOF skew & N/A & $-0.26{ }^{\circ} \mathrm{C}^{3}$ & $-0.23{ }^{\circ} \mathrm{C}^{3}$ \\
\hline
\end{tabular}

In general SSTs are skewed more towards colder events and the amplitude (given roughly by the standard deviation) decreases the further west one goes in both the models and observations. Apart from the eastern shift in the AMOC off run both model runs are very similar. Historical observations compare favorably with the control run although the observations tend to have more variability in the western Pacific and a positive (warm event skew), rather than negative (cold event) skew. Historic observation data is taken from the NOAA website there are no changes in forcing in the control run. Historical observations were taken from the NOAA website http:// www.esrl.noaa.gov/psd/gcos_wgsp/Timeseries/Plot/index. htm.

\subsection{Dominant modes of variability in the tropical Pacific}

To determine the spatial modes of maximal variability we calculate the leading empirical orthogonal function (EOF) (the eigenvector of the covariance matrix associated to the largest eigenvalue) from monthly fields of sea surface temperature (SST). The monthly spatial SST fields are taken over the tropical Pacific region bounded by the box $\pm 20^{\circ}$ $\mathrm{N}$ and $130^{\circ} \mathrm{E}$ and $280^{\circ} \mathrm{E}$ which are deseasonalized by subtracting the long term monthly mean at each grid point. We calculate the covariance matrix for the full duration (150 years) of the control run and the last 300 years of the AMOC off run. The leading EOF and the proportion of the variance it accounts for within each run is shown in Fig. 3.
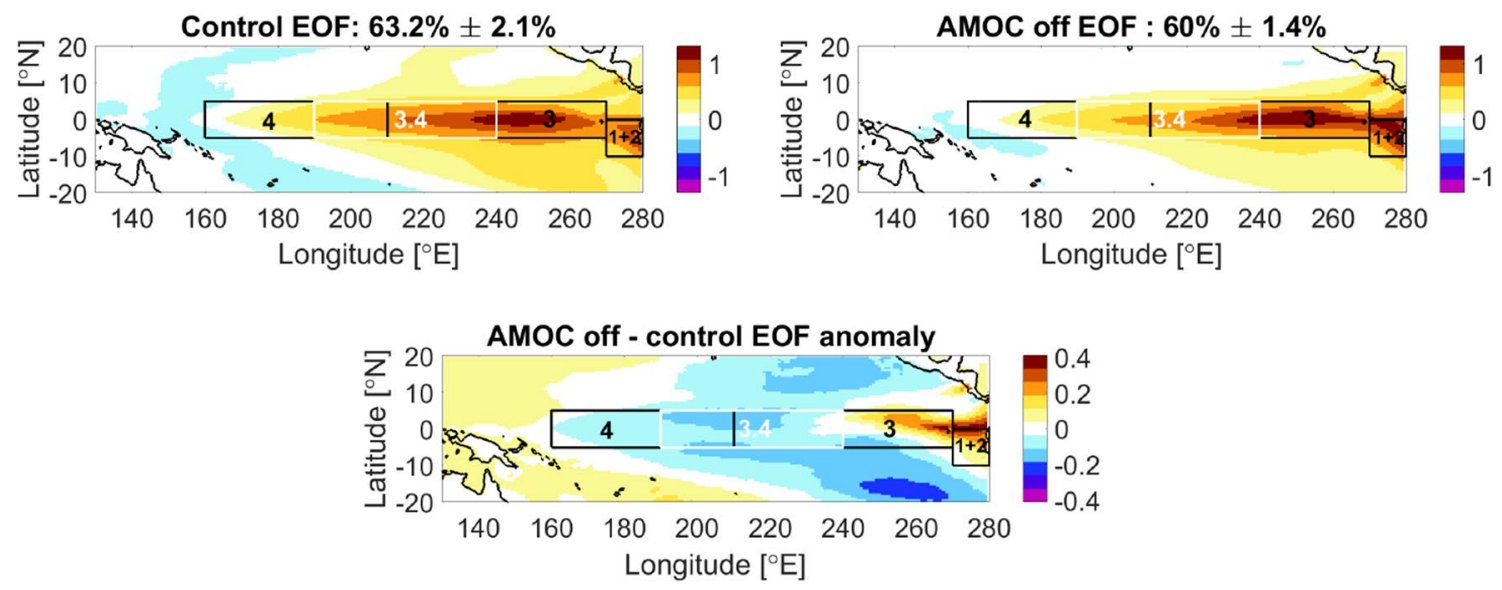

Fig. 3 The largest mode of variability (EOF) representative of ENSO in the deseasonalized monthly SST fields in the control (upper left) and AMOC off simulations (upper right). The proportion of the variance the mode accounts for within each run is shown as a percentage in the title above each plot with estimated error (North et al. 1995).
The lower row shows the anomaly between the runs. The EOF is shifted eastward in the AMOC off run. Units are ${ }^{\circ} \mathrm{C}$. Niño regions are indicated by the boxes. Moving east to west these are Niño $1+2$, Niño 3, Niño 3.4 (white box) and Niño 4. Most of the ENSO variability in the model is captured in Niño 3 
The second EOF associated to the Modoki mode (not shown) (Ashok and Yamagata 2009), accounts for about $15 \%$ of the variance in both runs.

The leading EOF in both the control and the AMOC off run is representative of the ENSO mode. Relative to the control run, the AMOC off ENSO EOF accounts for proportionally slightly less of the total variance in SST (60 versus 63\%) although this difference, both proportional and absolute, is within estimated error bounds. The spatial pattern however is shifted eastward and is slightly more equatorially confined as can be seen in the anomaly. We have tested that this spatial shift is significant at the $99 \%$ level. More specifically, the variance differences at each spatial location were tested for significance at the $99 \%$ confidence level by performing a two sample f-test on the deseasonalized spatial SST anomaly fields in both control and AMOC off runs. Most of the variability in both runs is contained in the Niño 3 region.

\subsection{ENSO amplitude and distribution}

We next look at the time series and amplitude distribution of the leading mode of SST variability as well as the distributions of the more traditional Niño $1+2,3,3.4$ and 4 indices. Time varying properties are analyzed by projecting the leading EOF onto the time ordered fields of deseasonlized monthly SST for both control and AMOC off runs. This produces a time series of how strong the spatial mode is at each point in time throughout the run and is much like a Niño index although it is more specific in that it captures the time varying properties of just this mode. The time series of the EOF projection are given in Fig. 4 (upper and lower left panel). The projection in the AMOC off run has some drift probably due to the long time taken for the deep ocean to re-equilibriate with the new AMOC off ocean mode. This drift is removed by linearly detrending the AMOC off EOF projection for calculation of the periodogram and autocorrelation functions in Sect. 3.4. This is to remove any spurious low frequency/long time scale correlations that a linear trend can introduce.

We have plotted the frequency of the value in the detrended EOF time series projection in Fig. 4 (lower right panel). We have also plotted the frequency of deasonalized SST anomalies in each of the Niño regions as a more traditional comparison with the leading EOF mode (Fig. 5). These values are the mean SST anomalies over the regions, going from tropical east Pacific to west shown in Fig. 3, Niño $1+2$ (equatorial South American Pacific coast, bounded by the box $0-10^{\circ} \mathrm{S}, 270-280^{\circ} \mathrm{E}$ ), Niño 3 (eastern tropical Pacific, $5^{\circ} \mathrm{S}-5^{\circ} \mathrm{N}, 210-270^{\circ} \mathrm{E}$ ), Niño 3.4 (central tropical Pacific, $5^{\circ} \mathrm{S}-5^{\circ} \mathrm{N}, 190-240^{\circ} \mathrm{E}$ ) and Niño 4 (western tropical Pacific, $5^{\circ} \mathrm{S}-5^{\circ} \mathrm{N}, 160-210^{\circ} \mathrm{E}$ ). In general distributions become narrower (less variability) and more skewed towards cold events the further west one goes. Both runs have very similar amplitudes, standard deviations and skewness although one can see a shift eastward in the Niño indices for the AMOC off runs which was also picked up by the spatial anomaly in the EOF. We have tabled the values of mean, standard deviation and skewness for the EOF projection and the Niño indices in Table 1. Amplitudes in the SST anomalies (seasonal mean removed) given approximately by the standard deviation are very similar although slightly lower in the AMOC off run.

\subsection{Spectra and autocorrelation of EOF projection}

In Fig. 6 (left panel) we calculate the smoothed periodogram of the linearly detrended EOF projection time series with 95\% confidence intervals and bandwidths given by the error bar. In the control run (thick blue line)
Fig. 4 Projection of the leading EOF in Fig. 3 on to the timeseries of the SST anomaly fields normalized by the standard deviation of the projection time series (AMOC off projection in the upper panel, control projection in the lower left panel). The lower right panel is the relative frequency of these values. The blue line is the control run and the red is the AMOC off run
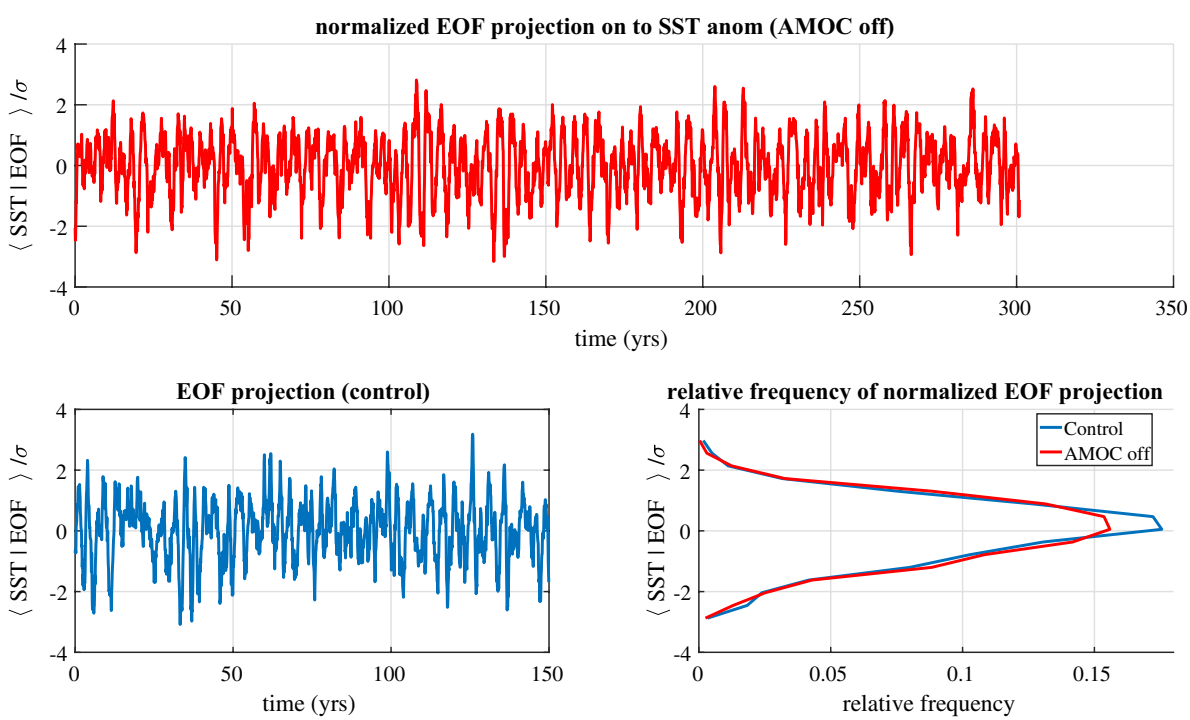

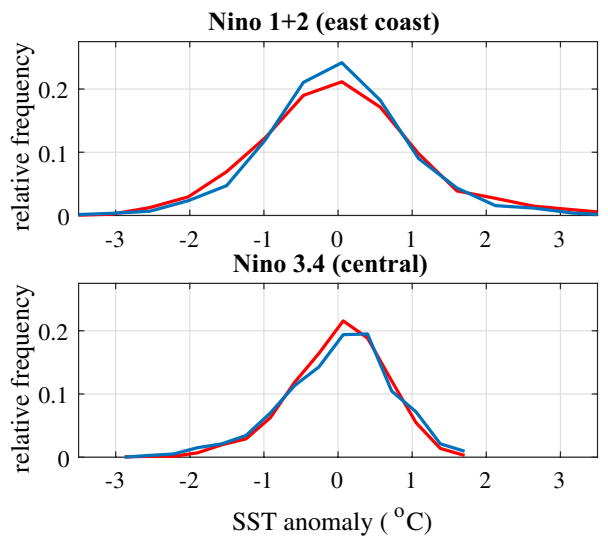

Fig. 5 Histograms of the deseasonalized SST anomalies in each of the Niño regions. Niño $1+2$ is situated just off the equatorial South American coast, Niño 3 is eastern equatorial Pacific, Niño 3.4 is central equatorial Pacific and Niño 4 is western equatorial Pacific. Blue lines are the control run and red lines are the AMOC off run. In gen-

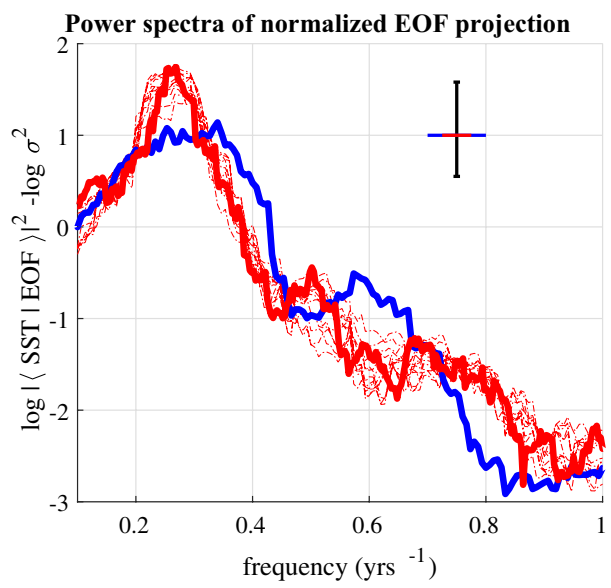

Fig. 6 Power spectra (left panel) of the linearly detrended normalized EOF timeseries in Fig. 4 and the autocorrelation functions (right panel). The thick blue lines are the control run and the thick red is the spectrum of all 300 years of the AMOC off run. The thin red lines are eleven 150 year segments of the AMOC off run spaced 15 years apart. The spectra are estimated by smoothing the raw periodograms (Daniell spectral estimator) with a rectangular window of 15 points (bandwidth of control run is $\Delta f=15 / 150=0.1$ cycles/year and

the leading EOF has a broad spectral peak of width $\sim 0.1$ cycles/year (approximately the bandwidth resolution) with a maximum at 0.34 cycles/year (a period of 2.9 years). The periodogram of the AMOC off run (thick red line) has a much sharper peak of width $\sim 0.05$ cycles/year (again, approximately the bandwidth) and maximum 0.26 cycles/ year corresponding to a period of 3.9 years. The sharper peak in the AMOC off run may be due to the longer time series giving a better estimate of the mean ENSO frequency. We have tested this by cutting the AMOC off time series to the same length as the control run (150 years) and
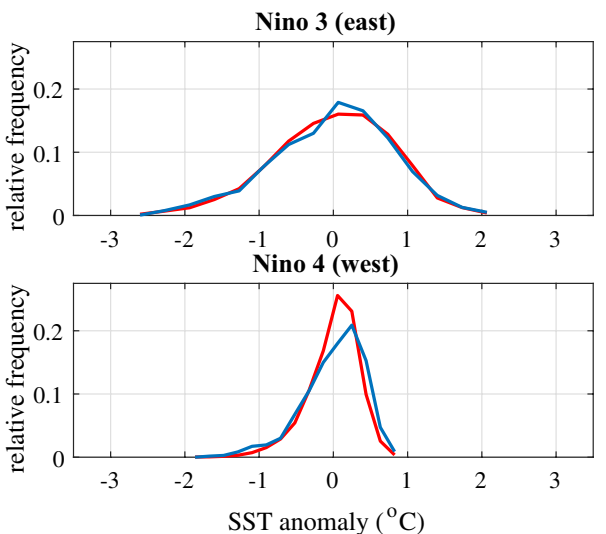

eral distributions become narrower (less variability) and more skewed towards cold events the further west one goes. This is also seen in observations (Table 1). Both runs have very similar amplitudes, standard deviations and skewness

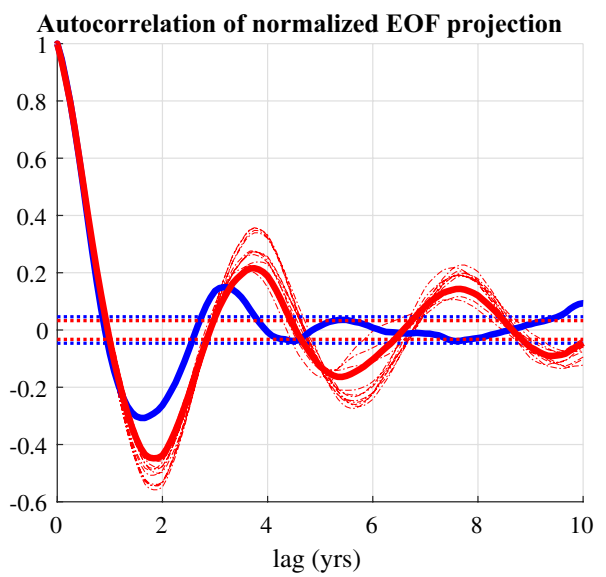

$\Delta f=15 / 300=0.05$ cycles/year for the AMOC off run and is plotted as the horizontal error bar). The vertical error bar is the $95 \%$ confidence interval. In the autocorrelation function plots dotted lines represent the $95 \%$ confidence interval of the null hypothesis. The EOF has clear periodicities, the AMOC off run being shifted to longer periodicities of just under 4 years compared of the control run which is closer to 3 years

computing the smoothed periodograms for 11 segments spaced 15 years apart (thin red lines). Peaks do get wider as expected however they were still narrower than the control run suggesting a more regular, less damped oscillation. There is also a shift to longer ENSO periods in the AMOC off relative to the control run which does appear to be significantly different.

An alternative way to look at the same information provided by the periodogram is the autocorrelation function of a time series, the difference being the information is presented in the time rather than the frequency domain. 
Autocorrelation functions are presented in the right panel of Fig. 6. The thick blue line is the control run and thick red line is the full 300 years of the AMOC off run. Thin red lines are the eleven 150 year segments of the AMOC off run spaced 15 years apart. Dotted lines represent the 95\% confidence interval for the null hypothesis. The autocorrelation has a clear, damped oscillatory character. This is particularly prominent in the AMOC off run with multiple cycles of period 45 months having greater correlation than the $95 \%$ confidence bound of the null hypothesis. This supports the sharper, more regular, ENSO thought to be present from periodogram analysis. In contrast the control run had a broader peak centered around a 38 month period. The oscillation in the autocorrelation function is washed out below the confidence interval after just one cycle in the control run suggesting that the ENSO period is more heavily damped in the control run.

\section{Mechanisms for differences in ENSO}

Having established that ENSO in the AMOC off run relative to the control has (1) a similar amplitude and distribution of SST anomalies, (2) a spatial pattern shifted eastward and (3) a longer, more regular period, we discuss mechanisms that could result in these differences.
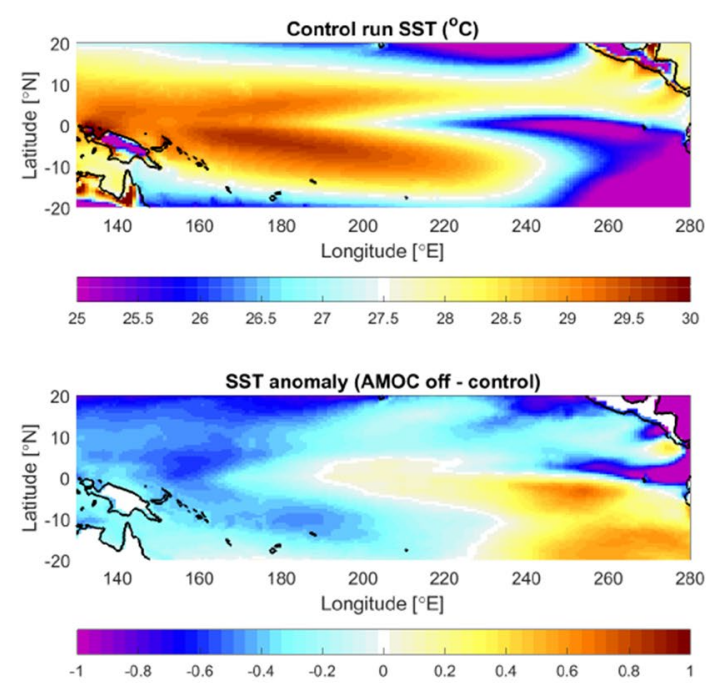

Fig. 7 Annual means of sea surface temperature (SST) in both runs and their difference. Also plotted is the mean SST integrated across $5^{\circ} \mathrm{S}-5^{\circ} \mathrm{N}$, control run (blue), AMOC off (red) and their difference, AMOC off-control (black). The gradient in SST between $200^{\circ}$ and $250^{\circ} \mathrm{E}$ is the same but is shifted slightly eastward visible in the anomaly (solid black line, lower right hand panel). The warm pool and western Pacific in the AMOC off run is cooler due to the anom-

\subsection{Eastward shift in ENSO}

The eastward shift in the ENSO mode in the AMOC off run is also accompanied by an eastward shift in the mean equatorial Pacific state. It seems likely therefore that the shift in SST variability results from the mode being shifted eastward with the mean state. We propose a mechanism for the shift in the mean state and then show the patterns in variability are also shifted east.

\subsubsection{Eastward shift in mean state}

An executive summary of basic mechanism of the shift in the Pacific mean state is as follows (we go into more detail in the following paragraphs): The anomalous north-south temperature dipole (Fig. 2) causes a north to south surface wind anomaly associated to the southward shift of the ITCZ (Fig. 8, lower right panel, dotted lines) as the higher pressure, cooler air in the northern hemisphere flows towards the rising lower pressure, warmer air in the southern hemisphere. This anomalous north to south surface wind exerts an anomalous north to south wind stress on the surface of the ocean and results in wind driven (Ekman) transport in the upper ocean waters. The transport is to the right of the wind stress vector in the northern hemisphere and to the left in the south. It is the anomalous eastern Ekman transport in the southern hemisphere (Fig. 9) that results in
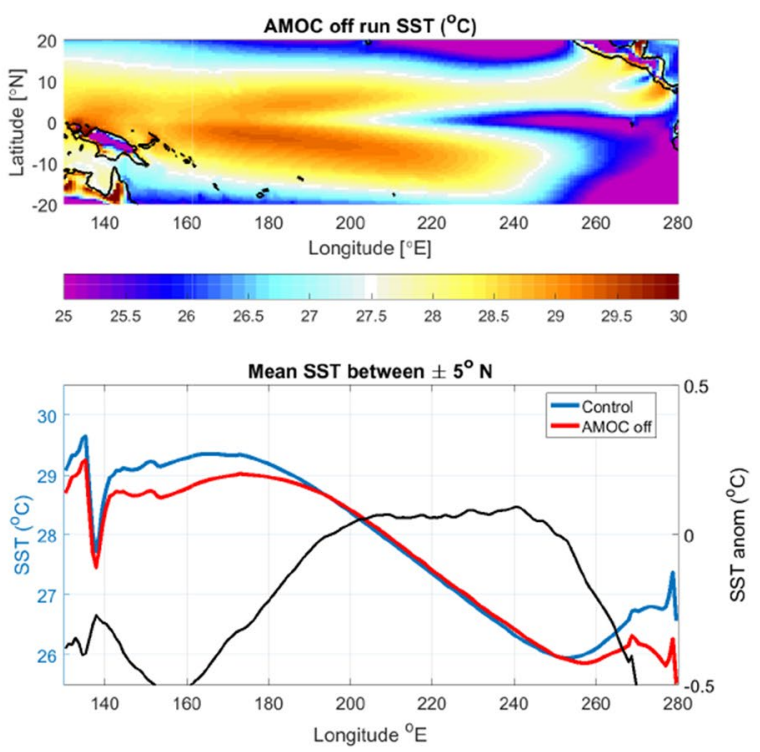

alous flow of cooler waters from the northern hemisphere while the cold tongue is slightly warmer due to the reduced upwelling from the deeper thermocline. The eastern equatorial coast has a northern cooling due to the influence of the anomalously cold North Atlantic whose influence is via the atmosphere while the south eastern equatorial Pacific is warmer due to the reduced upwelling 

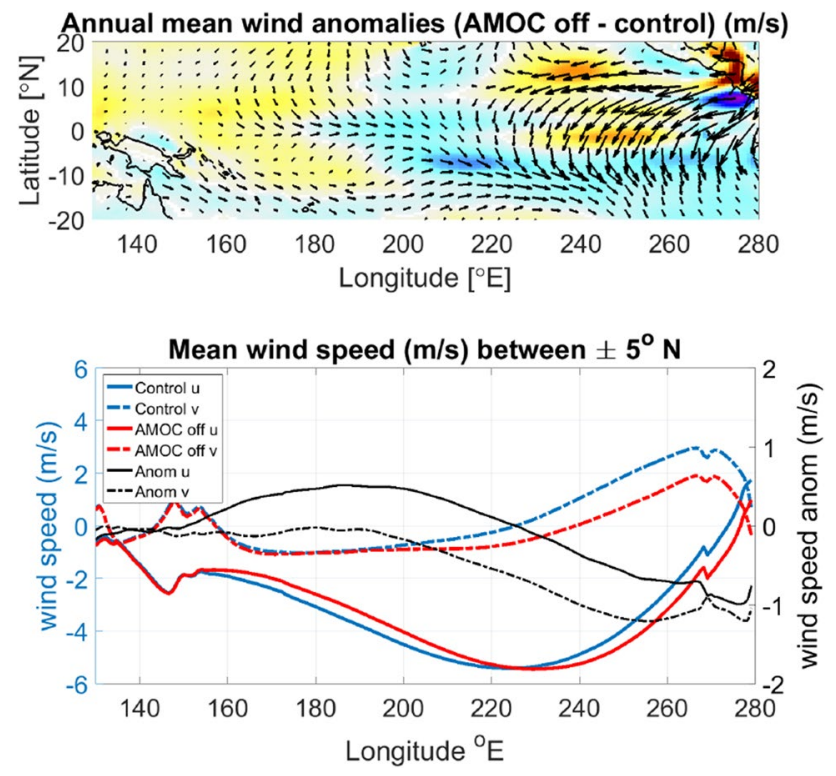

Fig. 8 Annual mean surface wind snomsly fields. In the upper panel, anomalies in absolute wind speed are given in the colour plot and the anomalies in wind direction and magnitude are given by the vectors. The bottom panel is the mean of the $u$ (eastward flow positive, solid line) and $v$ (northward flow positive, dotted line) components between $5^{\circ} \mathrm{S}$ and $5^{\circ} \mathrm{N}$ across the Pacific basin, the control run is blue, AMOC off red and the anomalies (AMOC off-control) of the wind components are in black. Dotted for $v$ anomalies and solid for $u$ anomalies

the eastward shift as a new east-west dynamic balance is reached.

Supporting evidence for this mechanism is presented next: in Fig. 7 SST fields in the equatorial Pacific for both runs and their difference are given. Note that the Pacific cold tongue is slightly warmer in the AMOC off run. In the bottom right hand corner we have plotted the annual mean SST integrated between $5^{\circ} \mathrm{S}$ and $5^{\circ} \mathrm{N}$ across the Pacific basin. The east west
SST gradient is the same in both simulations between $200^{\circ}$ and $250^{\circ} \mathrm{E}$, however the AMOC off run profile shows the eastward shift, visible as the minima and maxima in SST being shifted (red line, lower right panel). SSTs in the AMOC off run are also vertically offset to slightly lower values.

Figure 8 shows fields of annual mean wind vector differences and their mean components across the Pacific integrated between $5^{\circ} \mathrm{S}$ and $5^{\circ} \mathrm{N}$. The bottom right plot shows that the mean $v$ wind component is positive (northward flow) east of $240^{\circ} \mathrm{E}$ and is reduced in the AMOC off run east of $200^{\circ} \mathrm{E}$. This north blowing wind will cause westward Ekman transport of the surface waters in the southern hemisphere at the South America-equatorial east Pacific boundary and the upwelling of cooler, deeper waters lifting the thermocline. As this northward component is reduced in the AMOC off run a deeper thermocline is expected. Reduced upwelling of cooler waters would also suggest warmer SSTs which are generally observed (Fig. 7, lower left panel) particularly in the region of the east equatorial Pacific south of the equator where anomalous ENSO variability is concentrated. There is a localised anomalous cooling in the north east equatorial Pacific which results from its proximity to the much anomalously colder north Atlantic. This strong localized anomalous temperature dipole in the east Pacific will result in the anomalous north to south wind and the reduction in Ekman transport off shore. The eastward shift in the AMOC off annual mean equatorial Pacific state can also be seen from the mean $u$ wind component (Fig. 8, lower right panel, solid coloured lines).

Ekman transport, $\mathbf{M}=\left(M_{x}, M_{y}\right)$ and its divergence are diagnosed from the annual mean surface wind fields using

$M_{x}=\frac{\hat{\tau}_{y}}{f}$,

$M_{y}=-\frac{\hat{\tau}_{x}}{f}$,

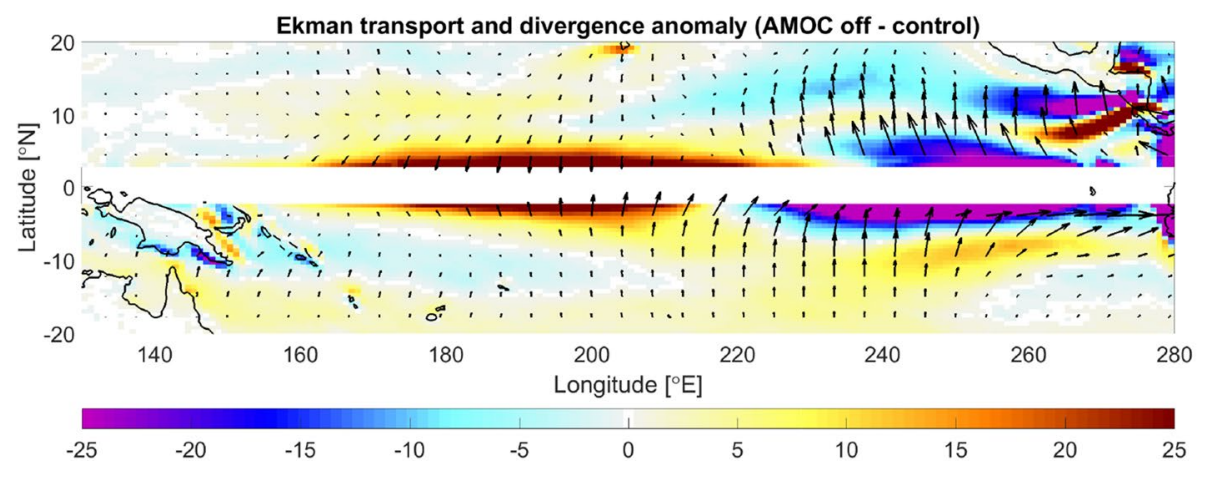

Fig. 9 Annual mean Ekman transport anomaly field and its divergence diagnosed from annual mean $u$ and $v$ wind component anomalies. Divergence of Ekman transport, $\nabla \cdot \mathbf{M}$ is the colour plot, negative values indicate downwelling and deepening thermocline. Vectors give the Ekman transport direction and magnitude. Note these plots have all constants set to 1 and are intended only to show changes in magnitude and direction. Ekman transport is not calculated in the $\pm 2^{\circ}$ $\mathrm{N}$ band of latitudes due to the Coriolis parameter $f$ being very small here 
where $f=2 \Omega \sin \phi$ is the Coriolis parameter, $\Omega$ is the angular rotation rate of the Earth, and $\phi$ is the latitude. Wind stress components, $\hat{\tau}_{x}, \hat{\tau}_{y}$ are diagnosed from the annual mean wind speed components such that $\hat{\tau}_{x} \propto u|u|$, $\hat{\tau}_{y} \propto v|v|$. We will only be interested in anomalies of $\mathbf{M}$ so all constants such as $2 \Omega$ etc will be set to 1 . A divergence of Ekman transport will result in a upward vertical current $w_{E}$ through conservation of mass $\left(w_{E}\right.$ is taken as positive upwards) and a shoaling of the thermocline i.e.

$\nabla \cdot \mathbf{M}=w_{E}$.

We plot both the anomalous Ekman transport (represented by the vectors) between the two runs and its divergence (negative values indicate convergence and a deepening thermocline, blue colours) in Fig. 9. Areas of anomalous Ekman transport convergence in the eastern equatorial Pacific (blue colours) and an anomalous eastward Ekman transport in the southern hemisphere east of $200^{\circ} \mathrm{E}$ (Ekman transport direction and magnitude are given by the vectors) can be seen. The transport is divergent in the western equatorial region (red colours).

\subsubsection{Eastward shift in variability}

The wind-evaporation-SST (WES) feedback (Xie and Philander 1994) may influence ENSO variability by altering the rate at which SSTs are damped by evaporative fluxes. Anomalies in evaporation are correlated with SST, wind speed and humidity anomalies that are present in the subtropics. Near the equator however, it appears that changes in Ekman transport and pumping are dominant. In Fig. 10 we show variability in latent heat flux is shifted eastward by linearly regressing SST anomalies in the Niño 3 against deseasonalised monthly spatial fields of upward latent heat flux. We have also linearly regressed Niño 3 SST against thermocline depth and $u$ wind which show the same eastward shift (figures not shown).

\subsection{Shift to longer ENSO period}

\subsubsection{Increased thermocline depth in eastern equatorial Pacific}

We expect the anomalous divergence (convergence) of Ekman transport to cause shoaling (deepening) of the thermocline. In Fig. 11 we plot the differences in thermocline depth that are significant at the $99 \%$ confidence level and the thermocline depth in both runs integrated between $5^{\circ}$ $\mathrm{S}$ and $5^{\circ} \mathrm{N}$ across the Pacific basin. Differences were tested for significance by performing a t-test on the spatial fields of the annual mean thermocline depth in each run. The difference in annual mean thermocline depth change is of the same order as the ocean vertical resolution however it is significant. One sees a deepening of the thermocline in the east Pacific concentrated in the region of large ENSO variability as expected from the changes in the wind fields and the Ekman transport divergence. This increased thermocline depth in the east will increase the heat capacity in this region.

Nino 3 SST against upward latent heat flux anom $(\mathrm{W} / \mathrm{m} 2 / \mathrm{oC})$
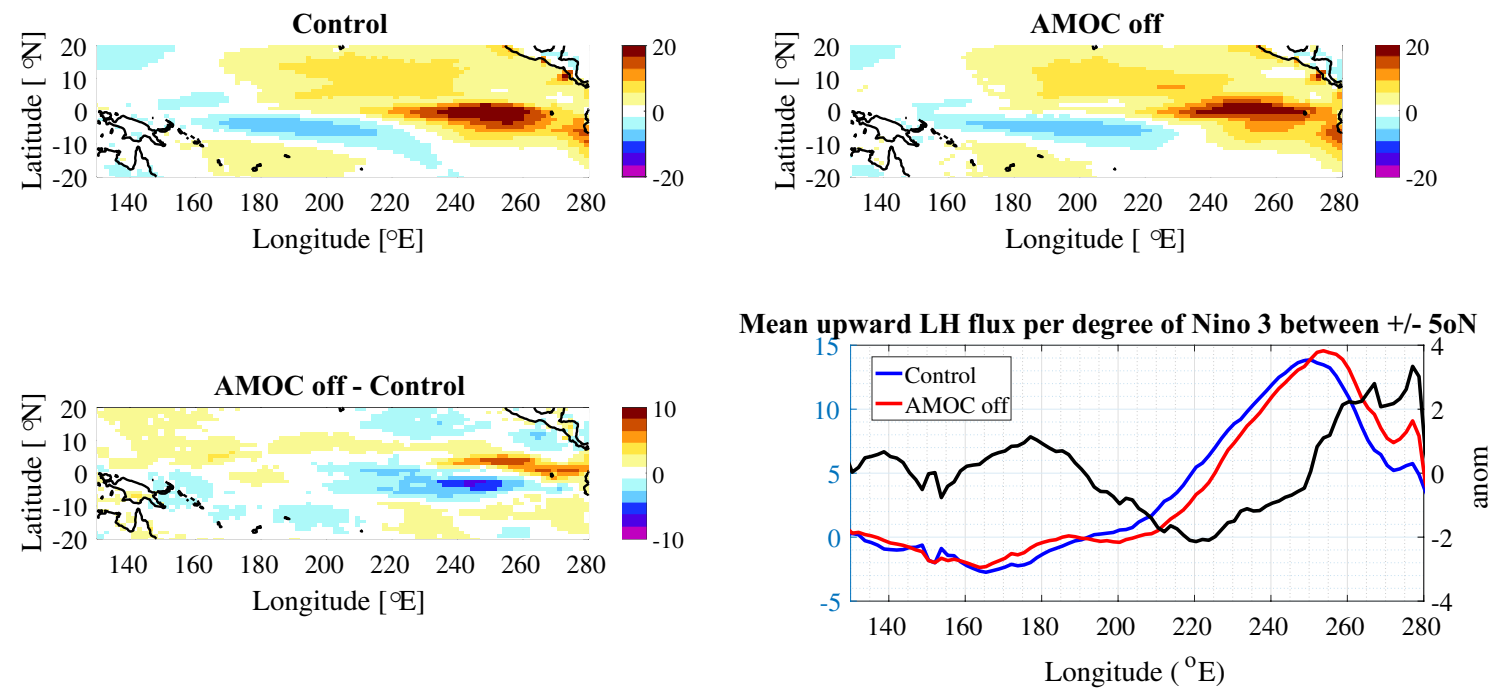

Fig. 10 Linear regression of Niño 3 SST against monthly spatial fields of upward latent heat flux $\left(\mathrm{W} / \mathrm{m}^{2} /{ }^{\circ} \mathrm{C}\right)$. The upper left panel is the control run, upper right is the AMOC off run, bottom left is the

difference. The bottom right is the mean between $\pm 5^{\circ} \mathrm{N}$, the blue line is the control run, the red is the AMOC off run and the black line is their difference 


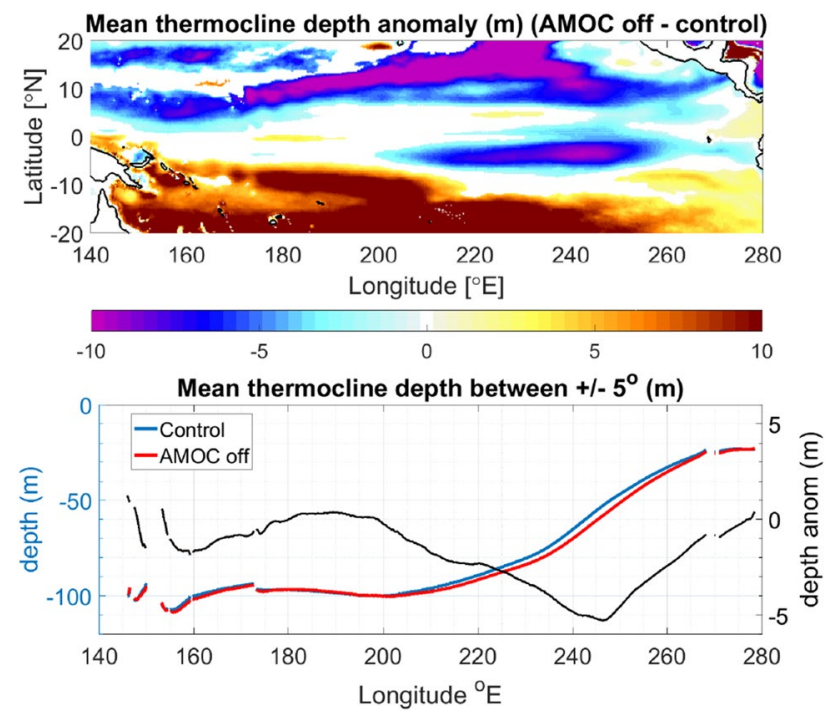

Fig. 11 Mean thermocline depth anomaly spatial patterns in the top panel between AMOC off and control run. Increasing depth means increasingly negative values. We have only plotted the differences that are significant above the $99 \%$ confidence level using a t-test. The thermocline is deeper in the eastern equatorial Pacific where most of the ENSO variability occurs. The lower panel shows annual mean thermocline depth across the Pacific basin integrated between $5^{\circ} \mathrm{S}$ and $5^{\circ} \mathrm{N}$ in the control run (blue) and AMOC off run (red) and their difference (AMOC off-control) in black

The deeper thermocline in the east equatorial Pacific should also mean this region will respond slower to changes in SATs or radiative surface fluxes due to the increased heat capacity. Using a simple, analytically tractable linear ENSO model (Jin's 1997 recharge oscillator) to qualitatively understand the behaviour of the much more complex climate model, we demonstrate the increased SST relaxation time can result in increased ENSO period.

\subsubsection{Jin (1997)'s recharge oscillator}

This model consists of two coupled variables, the thermocline depth anomaly in the west Pacific $h_{W}$ and the SST anomaly in the east of the Pacific $T_{E}$ which we take to be the Niño 3 SST anomaly or equivalently the leading EOF SST projection. Essentially, it models the slow ENSO dynamics as a damped harmonic oscillator excited by fast, random, atmospheric weather noise. We give the equations without detailed discussion or justification, full details can be found in Jin (1997). The recharge oscillator is completely described by (overdots denote differentiation with respect to time)

$\dot{h}_{W}=-r h_{W}-\alpha b T_{E}-\alpha \xi_{1}$,

$\dot{T}_{E}=-c T_{E}+\gamma b T_{E}+\gamma h_{W}+\gamma \xi_{1}+\xi_{2}$.
The parameter $r$ is the relaxation rate of the western Pacific thermocline anomaly that collectively represents the damping of the upper ocean through mixing and energy loss at the boundaries through propagation of Kelvin and Rossby waves. $\alpha$ is a coupling constant for Sverdrup transport and wind stress and is set to $\alpha=r / 2$ to give a mean thermocline anomaly of zero. $b$ is a coupling constant that relates east to west wind stress to eastern Pacific SST anomalies when in equilibrium i.e. a positive $T_{E}$ gives rise to an anomalous west to east wind stress. The relaxation rate of the eastern Pacific SST anomaly towards climatology is given by $c$. $c$ will be reduced by an increased thermocline depth and this is the parameter changed later on in the section. $\gamma$ represents thermocline depth-SST feedback and $\xi_{1}$ and $\xi_{2}$ are stochastic forcing by random wind stress and random heating respectively. Both are represented by random variables with Gaussian distributions and with respective standard deviations $\sigma_{1}$ and $\sigma_{2}$.

The two first order ordinary differential equations (ODE) (Eq. 4) can be rewritten as a single second order ODE of only variable $T_{E}$ in the standard form of a forced damped harmonic oscillator. This form will be most convenient for our purpose.

$\ddot{T}_{E}+2 \delta \dot{T}_{E}+\omega_{0}^{2} T_{E}=\tilde{\xi}(t)$,

$\omega_{0}^{2}=\alpha b \gamma-r R$ and the term on the right hand side is the new stochastic forcing term given by $\tilde{\xi}=\gamma(r-\alpha) \xi_{1}+r \xi_{2}+\gamma \dot{\xi}_{1}+\dot{\xi}_{2}$. In the absence of random forcing $(\tilde{\xi}(t)=0)$ one finds the eastern SST anomaly $T_{E}$ solution has damping $\delta$ given by

$\delta=-\frac{1}{2}(R-r)$

where $R=\gamma b-c$ and angular frequency of the oscillation, $\omega$

$\omega=\sqrt{\omega_{0}^{2}-\delta^{2}}$

\subsubsection{Parameter values}

Jin's recharge oscillator only distinguishes east and west and does not model spatial changes only changes in amplitude and frequency. It also only models the slow ENSO dynamics. Although the ENSO spatial structure changes in the AMOC off run it is a small change (an eastward shift in the EOF) and the division in the simple model between east and west is still appropriate. In fact very little has changed between the two runs in the equatorial Pacific implying many of the simple model parameters are equal for the two HadGEM3 runs. Apart from the eastward shift in ENSO and the mean state, the other change is the mean depth of the thermocline in the eastern equatorial Pacific. This depth 
change should affect $c$, the relaxation time of eastern Pacific SST anomalies. $\delta$, the decay rate of the ENSO oscillation and $\omega$ the ENSO oscillation frequency (both functions of c) are the other parameters that are different between the runs and these two parameters are directly measured from the autocorrelation function.

Where possible, we fit the model parameters to those inferred in the HadGEM3 model runs otherwise we use Jin's 1997 original values. The original parameter values used are $\gamma=0.0187^{\circ} \mathrm{C} / \mathrm{m} /$ month and $r=1 / 8 /$ month giving $\alpha=1 / 16 /$ month and these are the same for both AMOC off and control runs.

Parameter $b$ is estimated from HadGEM3 and it is approximately the same in both AMOC off and control runs. It is a measure of east to west thermocline depth difference when in balance with the west to east wind stress resulting from an east to west temperature difference. Specifically it is comes from the following equation in Jin's original paper

$h_{E}=h_{W}+\hat{\tau}_{x}$,

$\hat{\tau}_{x}$ is proportional to the zonally integrated wind stress anomaly which is parameterized as $\hat{\tau}_{x}=b T_{E}$ assuming $T_{W}=0$ i.e. there is no western Pacific SST anomaly, all the SST change is in the east and this east to west temperature difference produces an west to east wind stress. This relation assumes the pressure gradient force associated with the difference in east to west thermocline depth is in balance with the wind stress force resulting from the east to west temperature difference. $b$ is difficult to estimate from regressions of east to west thermocline depth difference versus east to west temperature difference using the HadGEM3 simulations as the model never reaches a true equilibrium between the thermocline depth difference and the wind stress at a given time due to the different adjustment time scales (and therefore lags) of the SST and thermocline depths in the east and west Pacific. We have performed these regressions however poor correlation $\left(r^{2}<0.5\right)$ and time lag between the variables were found resulting in low values $\left(10 \mathrm{~m} /{ }^{\circ} \mathrm{C}\right)$ of the coupling $b$. Instead we use the mean state (mean east to west thermocline depth difference versus mean east to west SST difference) to estimate this parameter as this should be a good estimate of the equilibrium state. In Jin's original paper, $b=b_{0} \mu$ and $b_{0}$ is set to give $50 \mathrm{~m}$ of thermocline depth difference per $1^{\circ} \mathrm{C}$ of east-west SST difference and notes this may be high end estimation of $b$. To study the model sensitivity to the value of $b$, he introduces the adjustable parameter $\mu$ to span high and low couplings. From Figs. 7 and 11 we estimate $b$ to be $80 \mathrm{~m}$ of east-west thermocline difference per $3^{\circ} \mathrm{C}$. This corresponds to a value of $\mu \approx 0.5$.

The damping parameter, $\delta$, can be estimated from the autocorrelation function in Fig. 6 and is different in each run. The $T_{E}(t)$ solutions of Eq. (5) are under-damped and oscillatory showing decaying oscillations of frequency $\omega$ from their initial value with an $e$-folding decay time scale ('the oscillation decay envelope') of $\tau=1 / \delta$. With the introduction of stochastic forcing by $\tilde{\xi}$ the damped oscillator will be continually perturbed and the resulting response will be a superposition of all of the individual decaying oscillation responses. The autocorrelation function allows one to see this response when the ENSO mode is subjected to this type of stochastic forcing (Fig. 6). It is apparent from this figure that the AMOC off run is less damped (longer $\tau$ ) than the control run as the oscillations decay more slowly. We can estimate these decay $e$-folding timescales (and equivalently $\delta$ ) from these plots. We estimate the timescale in the control run to be $\tau_{c} \approx[1.4,1.7]$ years and $\tau_{o} \approx[2.3,2.9]$ years in the AMOC off run from Fig. 6 by fitting a decay envelope of the form $e^{-t / \tau}$ to the peaks in the autocorrelation function.

As mentioned previously, $c$, the relaxation rate towards climatology of $T_{E}$ will be reduced by an increase in eastern Pacific thermocline mean depth. Assuming all the change in $\delta$ in the two runs is due to a change in $c$ we can estimate $c$ using the values of $\tau$ and the inferred constants from Eq. (6). We find $1 / c_{c}=[2.16,2.27]$ months in the control run and $1 / c_{o}=[2.41,2.50]$ months in the AMOC off run roughly a $[6,13 \%]$ decrease relative to the control run in $c$. This is slightly longer, but comparable to Jin's original value of 2 months. As an independent consistency check, $c$ should be inversely proportional to the change in thermocline depth, $d$ i.e. $c_{o} / c_{c} \approx d_{c} / d_{o}$. From Fig. 11 the mean thermocline depth anomaly in the eastern Pacific region is about $10 \mathrm{~m}$ and the mean depth is about $60 \mathrm{~m}$ so the change in $d_{c} / d_{o}$ is roughly a $14 \%$ decrease so consistent with the change in $c$ inferred from the change in $\delta$.

\subsubsection{Implied ENSO period from changes in c and sensitivity to parameter values}

With these inferred values of the simple model's constants we can calculate the implied oscillation frequency (or equivalently period, $P=2 \pi / \omega$ ) for each run using Eq. (7). The calculated period of the control run is $P_{c}=[40,41]$ months compared to the 38 month period estimated for HadGEM3 from the autocorrelation function. The calculated period of the AMOC off run is $P_{o}=[43,44]$ months compared to HadGEM3's 45 month period i.e. the change in mean thermocline depth results in $P_{o}>P_{c}$.

We have studied the sensitivity of the result $P_{o}>P_{c}$ due to changes in thermocline depth on the value of the various parameters in Jin's (1997) model.

The sensitivity to the value of $b=b_{0} \mu$ is made by varying $\mu$ to span very low wind stress-thermocline depth difference coupling $\left(\mu=0.2, b=10 \mathrm{~m} /{ }^{\circ} \mathrm{C}\right)$ to high coupling 
$\left(\mu=1, b=50 \mathrm{~m} /{ }^{\circ} \mathrm{C}\right)$. Throughout the range of high to low couplings $P_{o}>P_{c}$ although absolute numbers change from $P_{c} \approx 77$ months to $P_{o} \approx 115$ months at $\mu=0.2$ to $P_{c} \approx 27$ months and $P_{o} \approx 28$ months at $\mu=1$. These values correspond to proportional decreases in $c_{o} / c_{c}$ of $25 \%(\mu=0.2)$ to $5 \%(\mu=1)$. Values of around $\mu \sim 0.5$ give reasonable agreement with HadGEM3 results.

In the equations for $\delta$ and $\omega, \gamma$ and $b$ never appear on their own, only as the product $\gamma b$. Therefore the sensitivity analysis of $b$ is equivalent to the sensitivity of $\gamma$ relating to the SST-thermocline depth feedback.

We have also tested the sensitivity of the result to the remaining parameter $r$, related to the adjustment time of the thermocline anomaly in the western Pacific. Fixing $r$ also fixes $\alpha$ which parameterizes the adjustment by Sverdrup transport. By making $r=\mu_{r} r_{0}\left(r_{0}=1 / 8 /\right.$ month $), \mu_{r}$ is varied between 0 and 2 to span long and short adjustment times. Provided $r>1 / 24 /$ month corresponding to $\mu_{r}=0.34, P_{o}>P_{c}$. At $r \sim 1 / 24$ the two ENSO periods are the same, having the value $P_{c}=P_{o} \sim 63$ months. The ratio $c_{o} / c_{c}$ is relatively insensitive to the value of $r$ with proportional decreases of $8 \%$ for low values of $r$ (slow adjustment of the thermocline anomaly) and $13 \%$ for high values (fast adjustment).

This demonstrates an increase in the relaxation time of the eastern Pacific anomaly, $1 / c$, in this region of the recharge oscillator's parameter space results in an increase in ENSO period.

\subsection{Simultaneous decreases in damping and stochastic forcing resulting in little change in ENSO amplitude}

Regarding ENSO as a stochastically forced under-damped harmonic oscillator, the decreased damping rate in the AMOC off run should have some other observable consequences: (1) peaks in the power spectra should be narrower and higher and located at frequency $\sqrt{\omega^{2}-\delta^{2}}$. (2) Oscillations should have a longer coherence time in the autocorrelation function and (3) given the same magnitude of stochastic forcing, the mean amplitude of the response should be larger. (1) and (2) are observed in Fig. 6 however (3), the amplitudes of the ENSO modes in each run are roughly the same in the control and AMOC off runs (Table 1, Niño 3 SST anomaly or EOF standard deviation).

Since these are conceptual arguments additional approximations on the stochastic forcing of Eq. (5) are made. That is, $\tilde{\xi}$ is taken to be a Gaussian random variable with standard deviation $\tilde{\sigma}$ rather than having separate $\xi_{1}$ and $\xi_{2}$ terms and their time derivatives for ease of interpretation (a full calculation brings the following estimates of std $\left(T_{E}\right)$ in each run closer together but adds nothing but complication to the points following). According to this model, the ENSO standard deviation should be proportional to

$\operatorname{std}\left(T_{E}\right) \propto \frac{\tilde{\sigma}}{\sqrt{\delta \omega}}$

That is, ENSO amplitude is a function of the magnitude of the noise forcing, $\tilde{\sigma}$, the damping $\delta$ and angular frequency $\omega$ . This relation implies that if the magnitude of the noisy forcing was the same for both AMOC off and control runs (superscript $o$ and $c$ respectively), $\tilde{\sigma}^{c}=\tilde{\sigma}^{\circ}$, one should see $\frac{\operatorname{std}\left(T_{E}^{\circ}\right)}{\operatorname{std}\left(T_{E}^{c}\right)}=[1.27,1.57]$ i.e. $27-57 \%$ higher ENSO amplitude in the AMOC off run, a significant change that is not observed in the model simulations (we have used the HadGEM3 observed values of $\omega$ and $\delta$ in each run for this calculation). Another possibility is the stochastic forcing terms are significantly smaller in magnitude in the AMOC off run to offset the increased tendency to oscillate from the reduced damping. Using this as a hypothesis and setting the standard deviations in $T_{E}$ to be equal for the inferred parameter sets for each of the simulations implies $\tilde{\sigma}^{\circ} / \tilde{\sigma}^{c}$ should be $[0.64,0.79]$ times smaller in the AMOC off run.

We look directly for this change in stochastic forcing guided by the terms $\xi_{1}$ (random wind stress) and $\xi_{2}$ (random heating in the east Pacific) in Eq. (4) by linearly regressing deseasonalized proxies for $\xi_{1}$ and $\xi_{2}$ against the the Niño 3 SST anomaly. The regression is done to remove the dependence of these proxies on ENSO. The standard deviation of the residual of these regressions is attributed as the stochastic term. As a proxy for $\xi_{1}$ (random wind stress), the square of wind speed in the region overlapped by the Niño 3.4 and Niño 4 regions is taken. The residual standard deviation is found to be 0.67 times smaller in the AMOC off run. The proxy for $\xi_{2}$ (random heating in the east Pacific) is taken to be net surface shortwave flux in the Niño 3 region. The residual standard deviation is 0.86 times smaller in the AMOC off run. Both of these proxies are close to the estimated range suggesting the reduction in stochastic forcing could offset the decreased damping with the result of little change in ENSO amplitude.

The above analysis points towards the lack of change of amplitude in the AMOC off run being a result of a reduction in stochastic forcing being offset by a reduction in the damping of SST anomalies. We note however that there are multiple frameworks for assessing the contribution of individual ENSO processes and feedbacks to the amplitude of events in the real world and in models. This is just one and other methods, be they linear or non-linear, might yield different conclusions. A comprehensive comparison of all methods of quantifying ENSO feedbacks is not possible here, hence we present this analysis as support, but not proof, of the hypothesis. 


\section{Discussion}

There have been three other ENSO studies of hosed coupled GCMs that we are aware of, those of Timmerman et al. (2007), Dong and Sutton (2007) and Svendsen et al. (2014). Timmerman et al. (2007) used five different CMIP3 era models (GFDL CM2.1, NCAR CCSM2, NCAR CCSM3, MPI-OM1 and HadCM3) while Dong and Sutton (2007) looked in more detail at a single model (HadCM3). All 5 models in Timmerman et al. (2007) had significantly increased ENSO amplitudes as measured by the power spectra of the SST anomalies in the Niño 3 region. We do not find significant differences in amplitudes in HadGEM3 although peaks in its spectra were narrower and more defined suggesting that HadGEM3 has a decreased ENSO damping when the AMOC is off. Reduced damping may be the likely cause of the increased amplitude in the CMIP3 models although this would have to confirmed via more persistent oscillations in their autocorrelation functions. However, the increase of peaks without broadening in the CMIP3 model's power spectra suggest their ENSOs become more periodic and less damped. If the increase in the peaks were due to increased broadband stochastic forcing one would expect the whole spectrum to be amplified.

HadCM3 may be considered a CMIP3-class model. In general, CMIP5-class models show an improvement in terms of representing both the properties of ENSO (amplitude, frequency, spatial pattern) and the physical processes and feedbacks which are responsible for generating and maintaining the oscillation (Bellenger et al. 2014). However, there still exists a wide diversity of ENSO properties and processes in the CMIP5 models which has led to a number of different efforts to coordinate and improve models (Guilyardi et al. 2016). HadGEM3 has been developed to be submitted to CMIP6 and, in this configuration, represents a significant enhancement in resolution. The diagnostics of ENSO presented here indicate a ability to simulate the mode that is competitive with other models of similar resolution. Further work is underway to assess processes and to isolate the impact of resolution (Haarsma et al. 2016).

In 4 out of the 5 CMIP3 models a significant weakening in the eastern tropical Pacific annual cycle was also found [the AMOC off run annual cycle peaks are between 0.56 and 0.71 times smaller than the control as estimated from Niño 3 power spectra, Figure 6 in Timmerman et al. (2007)], the exception being MPI-OM1 where it was approximately the same. We also find a significant weakening in the eastern tropical Pacific annual cycle in HadGEM3 (figure not shown). The peak in the Nino 3 SST power spectrum is peak is 0.63 times smaller in the AMOC off run, about the same as the decrease found in the stochastic forcing. Guilyardi (2006) reported an inverse relationship between ENSO amplitude and strength of the seasonal cycle for CMIP3 models. HadGEM3 does not follow this relationship.

Thermocline depth and $u$ wind anomaly patterns in the tropical Pacific differ between the CMIP3 models. HadCM3 and GFDL CM2.1 showing thermocline shoaling in the western Pacific and deepening in the east. Across the entire tropical Pacific CCSM2 and CCSM3 show deepening while MPI-OM1 has significant thermocline shoaling. Wind anomaly patterns reflect the changes in thermocline depth. The simulations reported here are most similar to HadCM3 and GFDL CM2.1 with respect to the thermocline and $u$ wind change patterns although there is no thermocline shoaling in the western Pacific in HadGEM3, it remains approximately unchanged in this model. In all models apart from MPI-OM1 there is a deeper thermocline in the eastern Pacific.

Dong and Sutton (2007) look at the HadCM3 runs in more detail. It is an earlier incarnation of the model used in this study and these simulations have a lot of similarity with HadGEM3 even though the ocean model is very different. In particular they find the ENSO mode is shifted eastward and the annual cycle is also reduced (it is about 0.56 times smaller as estimated from Niño 3 power spectra, figure 6 in Timmerman et al. (2007) which is comparable to 0.63 found in HadGEM3). However ENSO amplitude increased significantly to 1.3 times the control run in HadCM3.

From the power spectra in Timmerman et al. (2007) it appears that there is no change in ENSO period for most CMIP3 models. Only GFDL CM2.1 has a shorter ENSO period in the AMOC off run. HadGEM3 has an increased period.

Using Jin (1997)'s stochastically forced damped harmonic oscillator model of the slow ENSO dynamics we argued how one could understand the results presented in this manuscript. That is, the dominant effect is the deeper thermocline in the eastern Pacific increasing the eastern Pacific ocean relaxation time and so increasing the period of the ENSO cycle. We fitted these model parameters from the HadGEM3 simulations of thermocline slope and estimated the ENSO damping rate $\delta$ from the autocorrelation functions of the ENSO mode time series. The estimated damping rate allowed us to infer the eastern Pacific relaxation rate and this was consistent with the observed change in thermocline depth in this region. Jin (1997)'s model makes predictions as to what one should observe in the more complex model, that is, narrower more defined peaks in the power spectra and a lengthened ENSO period which were observed.

Roughly, ENSO amplitude in Jin (1997)'s model should be $\operatorname{std}\left(T_{E}\right) \propto \frac{\tilde{\sigma}}{\sqrt{\delta \omega}}$ where $\tilde{\sigma}$ is the standard deviation of the stochastic forcing (the actual relation is a bit more 
complicated in Jin's model due to the way the stochastic forcing is added to the model equations). This means reduced damping should give larger ENSO amplitudes if $\omega$ and $\tilde{\sigma}$ are fixed. Alternatively, reductions in stochastic forcing along with decreased damping can give rise to the same ENSO amplitude. If $\tilde{\sigma}$ is proportional to the amplitude of the annual cycle in the eastern Pacific in other models (as it was in HadGEM3) this could also explain the increased amplitude found in the other models i.e. the reduction in stochastic forcing magnitude is outweighed by the decrease in damping. This would have to be confirmed via autocorrelation functions and measurements of stochastic forcing in the other models. As argued above, from the CMIP3 model's power spectra it seems likely that their ENSOs become less damped and more periodic. If confirmed this would imply the resulting ENSO amplitude could depend heavily on just three parameters; the measured $\delta, \omega$ and $\tilde{\sigma}$ in each CGCM.

Jin's simple linear stochastically forced damped oscillator model explains many of the features seen in these simulations. We should also mention this model has a nonlinear extension which also supports self sustained oscillations (limit cycles) when the wind stress temperature anomaly coupling becomes large through the $b$ parameter (Jin 1997). If ENSO were a noisy self sustained, rather than a stochastically excited damped oscillation, power spectra and autocorrelation functions would look very similar although the amplitude sensitivity to stochastic forcing would be reduced.

Although a shutdown of the AMOC is thought unlikely in the 21 st century, weakening is expected. The AMOC also has natural variability in its strength as witnessed by the Atlantic multidecadal oscillation. Yu et al. (2015) have suggested a link between AMO and El Niño location, stronger AMOC leading to more central El Niño events and conversely weaker AMOC to more eastern El Niño events, very similar to our findings.

\section{Conclusion}

In conclusion we have studied the changes in ENSO when the AMOC is in the off state in a high resolution, eddy resolving coupled CGCM and proposed a simple mechanism for the changes in the slow ENSO dynamics. We found the ENSO spatial pattern is shifted eastward and to longer oscillation periods although the its amplitude and distribution of SST anomalies remains approximately the same. The mechanism to explain these changes is as follows:

- When the AMOC is off an anomalous cold north-warm south hemisphere temperature dipole results (Fig. 2).
- This induces a north to south anomalous surface wind (particularly strong near the South American coast because of the proximity to the N Atlantic, Fig. 8, lower panel, dotted lines).

- The anomalous surface wind causes a wind stress on the ocean surface and leads to an anomalous eastward Ekman transport just south of the equator shifting the mean equatorial Pacific state and with it the ENSO mode east (Fig. 9).

- Anomalous convergences in Ekman transport close to the south American coast deepen the thermocline in the east Pacific, increasing the temperature anomaly relaxation time and therefore lengthening the ENSO period (Fig. 11).

The increase in ENSO period is backed up using a simple model of ENSO as a stochastically forced damped oscillator. This model makes additional predictions including a narrower spectral peak, more regular oscillation (decreased oscillation damping) and reduced stochastic forcing which are observed.

Previous studies with older, lower resolution CMIP3 era models show similar behaviour, particularly an earlier generation of this model, HadCM3. However, they all show increased ENSO amplitude. Using the simple model, one can potentially understand the differing responses in the slow ENSO dynamics as a competition between the decrease in damping tending to increase amplitude and the decrease in forcing tending to decrease the amplitude. In HadGEM3 the decrease in damping is being offset by the reduction in forcing. From Eq. (9), this would imply the resulting ENSO amplitude could depend on just the damping $\delta$, the frequency $\omega$ and magnitude of the stochastic forcing $\tilde{\sigma}$ in each CGCM.

Acknowledgements The research leading to these results has received funding from the European Union Seventh Framework Programme FP7/2007-2013 under Grant agreement no. 603864 (HELIX). MC acknowledges funding from NE/N018486/1. We would also like to thank Richard Betts, Peter Cox, Matt Hawcroft and Laura Jackson for useful conversations.

Open Access This article is distributed under the terms of the Creative Commons Attribution 4.0 International License (http:// creativecommons.org/licenses/by/4.0/), which permits unrestricted use, distribution, and reproduction in any medium, provided you give appropriate credit to the original author(s) and the source, provide a link to the Creative Commons license, and indicate if changes were made.

\section{References}

Ashok K, Yamagata T (2009) The El Niño with a difference. Nature 461:481-484 
Bellenger H, Guilyardi E, Leloup J, Lengaigne M, Vialard J (2014) ENSO representation in climate models: from CMIP3 to CMIP5. Clim Dyn 42:1999-2018

Clement AC, Peterson LC (2006) Mechanisms of abrupt climate change of the last glacial period. Rev Geophys 46:RG4002

Collins M, An SI, Cai W, Ganachaud A, Guilyardi E, Jin FF, Jochum M, Lengaigne M, Power S, Timmermann A, Vecchi G, Wittenberg A (2010) The impact of global warming on the tropical Pacific Ocean and El Niño. Nat Geosci 3:391

Collins M, Knutti R, Arblaster J, Dufresne JL, Fichefet T, Friedlingstein P, Gao X, Gutowski WJ, Johns T, Krinner G, Shongwe M, Tebaldi C, Weaver AJ, Wehner M (2013) Long-term climate change: projections, commitments and irreversibility. In: Stocker TF, Qin D, Plattner GK, Tignor M, Allen SK, Boschung J, Nauels A, Xia Y, Bex V, Midgley PM (eds) Climate change 2013: the physical science basis. Contribution of working group I to the fifth assessment report of the Intergovernmental Panel on Climate Change. Cambridge University Press, Cambridge

Demory ME, Vidale P, Roberts M, Berrisfor P, Strachan J, Schiemann R, Mizielinski M (2013) The role of horizontal resolution in simulating drivers of the global hydrological cycle. Clim Dyn 1:25

Dong B, Sutton RT (2007) Enhancement of ENSO variability by a weakened Atlantic thermohaline circulation in a coupled GCM. J Clim 20:4920-4939

Guilyardi E (2006) El Niño-mean state-seasonal cycle interactions in a multi-model ensemble. Clim Dyn 26:329-348

Guilyardi E, Wittenberg A, Balmaseda M, Cai W, Collins M, McPhaden M, Watanabe M, Yeh S (2016) Forth CLIVAR workshop on the evaluation of ENSO processes in climate models. ENSO in a changing climate. Bull Am Meteorol Soc 97:817-820

Haarsma RJ, Roberts M, Vidale PL, Senior CA, Bellucci A, Bao Q, Chang P, Corti S, Fučkar NS, Guemas V, von Hardenberg J, Hazeleger W, Kodama C, Koenigk T, Leung LR, Lu J, Luo JJ, Mao J, Mizielinski MS, Mizuta R, Nobre P, Satoh M, Scoccimarro E, Semmler T, Small J, von Storch JS (2016) High resolution model intercomparison project (highResMIP). Geosci Model Dev 9:4185-4208

Hewitt HT, Copsey D, Culverwell ID, Harris CM, Hill RSR, Keen AB, McLaren AJ, Hunke EC (2011) Design and implementation of the infrastructure of HadGEM3: the next generation Met Office climate modelling system. Geosci Model Dev 4:223-253

Hunke EC, Lipscomb WH (2010) CICE: the Los Alamos sea-ice model. documentation and user manual, version 4.1. Tech. Rep. LA-CC-06-012, Los Alamos National Laboratory

Jackson LC, Kahana R, Graham T, Ringer MA, Woollings T, Mecking JV, Wood RA (2015) Global and European climate impacts of a slowdown of the AMOC in a high resolution GCM. Clim Dyn 45:3299-3316

Jin FF (1997) An equatorial ocean recharge paradigm for ENSO. Part I: Conceptual model. J Atmos Sci 54:811

Madec G (2008) NEMO ocean engine. Tech. Rep. 27, Note du Pole de modelisation
Marotzke J, Willebrand J (1991) Multiple equilibria of the thermohaline circulation. J Phys Oceanogr 21:1372-1385

Mecking JV, Drijfhout SS, Jackson LC, Graham T (2016) Stable AMOC off state in an eddy-permitting coupled climate model. Clim Dyn. doi:10.1007/s00382-016-2975-0:1-16

Megann A, Storkey D, Aksenov Y, Alderson S, Calvert D, Graham T, Hyder P, Siddorn J, Sinha B (2013) GO5.0: the joint NERC-Met Office NEMO global ocean model for use in coupled and forced applications. Geosci Model Dev 6:5747-5799

North GR, Bell TL, Calahan RF, Moeng FJ (1995) Sampling errors in the estimation of empirical orthogonal functions. Mon Weather Rev 110:699-706

Rahmstorf S (2002) Ocean circulation and climate during the past 120,000 years. Nature 419:207-214

Rahmstorf S, Crucifix M, Ganopolski A, Goosse H, Kamenkovich I, Knutti R, Lohmann G, Marsh R, Mysak LA, Wang Z, Weaver AJ (2005) Thermohaline circulation hysteresis: a model intercomparison. Geophys Res Lett 32(L23):605

Rooth C (1982) Hydrology and ocean circulation. Prog Oceanogr 11:131-149

Stommel H (1961) Thermohaline convection with two stable regimes of flow. Tellus 13:224-230

Stouffer RJ, Yin J, Gregory JM, Dixon KW, Spelman MJ, Hurlin W, Weaver AJ, Eby M, Flato GM, Hasumi H, Hu A, Jungclaus JH, Kamenkovich IV, Levermann A, Montoya M, Murakami S, Nawrath S, Oka A, Peltier WR, Robitaille DY, Sokolov A, Vettoretti G, Weber SL (2006) Investigating the causes of the response of the thermohaline circulation to past and future climate changes. J Clim 19:1365-1387

Svendsen L, Kvamstø NG, Keenlyside N (2014) Weakening AMOC connects equatorial Atlantic and Pacific internnual variability. Clim Dyn 43:2931-2941

Timmerman A, Okumura Y, An SI, Clement A, Dong B, Guilyardi E, Hu A, Jungclaus JH, Renold M, Stocker TF, Stouffer RJ, Sutton R, Xie SP, Yin J (2007) The influence of a weakening of the Atlantic meridional overturning circulation on ENSO. J Clim 20:4899-4919

Vellinga M, Wood RA (2002) Global climatic impacts of a collapse of the atlantic thermohaline circulation. Clim Change 54:43-63

Williams KD, Harris CM, Bodas-Salcedo A, Camp J, Comer RE, Copsey D, Fereday D, Graham T, Hill R, Hinton T, Hyder P, Ineson S, Masato G, Milton SF, Roberts MJ, Rowell DP, Sanchez C, Shelly A, Sinha B, Walters DN, West A, Woollings T, Xavier PK (2015) The Met Office global coupled model 2.0 (GC2) configuration. Geosci Model Dev Discuss 8:521-565

Wittenberg AT (2009) Are historical records sufficient to constrain ENSO simulations? Geophys Res Lett 36(L12):702

Xie SP, Philander SGH (1994) A coupled ocean-atmosphere model of relevance to the ITCZ in the eastern Pacific. Tellus 46:340-350

Yu JY, Kao PK, Paek H, Hsu HH, Hung CW, Lu MM, An SI (2015) Linking emergence of the central Pacific El Niño to the Atlantic multidecadal oscillation. J Clim 28:651-662 